\title{
Hange-shashin-to Raises Levels of Somatostatin, Motilin, and Gastrin in the Plasma of Healthy Subjects
}

\author{
Takafumi Naito, ${ }^{*}$ Hiroki Itoh, Fumitaka Yasunaga, and Masaharu Takeyama \\ Department of Clinical Pharmacy, Oita Medical University, Hasama-machi, Oita 879-5593, Japan. \\ Received October 22, 2001; accepted December 5, 2001
}

\begin{abstract}
Hange-shashin-to has been used for chronic hypofunction of the gastrointestinal tract and to improve functional abnormalities of the upper and lower gastrointestinal system. To determine whether the pharmacological effects of Hange-shashin-to are due to gut-regulatory peptide levels, we developed a sensitive and specific doubleantibody enzyme immunoassay (EIA) for detecting motilin and also examined the levels of somatostatin-, motilin-, gastrin-, and vasoactive intestinal peptide (VIP)-immunoreactive substances (IS) in plasma from healthy subjects. We developed a sensitive $(3.5 \mathrm{pg}, 1.4 \mathrm{pg} /$ well) and specific (carboxy-terminal region) EIA for motilin. A single oral administration of Hange-shashin-to $6.0 \mathrm{~g}$ caused significant increases somatostatin-IS (20$60 \mathrm{~min})$, motilin-IS $(40 \mathrm{~min})$, and gastrin-IS $(40-90 \mathrm{~min})$ levels in plasma compared with levels in a placebo group. Hange-shashin-to had no significant effect on VIP-IS levels after single administration. These changes in hormone levels (somatostatin, motilin, and gastrin) might relate to normalization of the upper and lower gastrointestinal system by Hange-shashin-to.
\end{abstract}

Key words Hange-shashin-to; somatostatin; motilin; gastrin; EIA; Kampo

Somatostatin is a gastrointestinal motility regulator and functions as an inhibitor of hormone release in digestive organs. This peptide participates in the regulation of gastrointestinal motility with motilin. ${ }^{1-6)}$ Somatostatin as a gut regulatory peptide stimulates migrating motor complex (MMC)like activity and its analogue was the first to be used therapeutically among the gastrointestinal peptides. ${ }^{7)}$ Motilin, a peptide connected with somatostatin, has a powerful fundic pouch motor-stimulating activity and is one of the most important factors controlling the regular occurrence of phase 3 contractions of the MMC. ${ }^{8,9)}$ Another gut regulatory peptide, gastrin, stimulates acid secretion, and its release is mediated by various pathways such as direct stimulation of $G$ cells, mediation by cholinergic nerves, stimulation of gastrin-releasing peptide, stomach $\mathrm{pH}$, etc. ${ }^{10)}$

Vasoactive intestinal peptide (VIP) is widely distributed in the central and peripheral nervous system. This peptide has a vasodilating effect in many vascular beds, including the peripheral systemic and splanchnic beds and the cerebral arteries, and is an important neurotransmitter for the enteric nervous system. ${ }^{11,12)}$

Hange-shashin-to (EK-14), a Kampo herbal medicine, is prepared from seven crude herbs: Pinelliae Tuber, Scutellariae Radix, Zingiberis Rhizoma, Ginseng Radix, Glycyrrhizae Radix, Zizyphi Fructus, and Coptidis Rhizoma. Hangeshashin-to is frequently used for acute or chronic gastrointestinal catarrh, fermentative diarrhea, and acute gastroenteritis. This medicine has been clinically evaluated as more effective in the treatment of chronic hypofunction of the gastrointestinal system than is Rikkunshi-to in the treatment of hyperfunctioning conditions. Recently, Hange-shashin-to has been reported to be effective against diarrhea as a side effect of carcinostatic drugs. ${ }^{13)}$

Based on empirical effects of Kampo, some gut-targeting medicines have been determined to act at the gut regulatory hormone level. Ninjin-to, Rikkunshi-to, and Dai-kenchu-to affect gastrointestinal motility and based on empirical evidence their effects are assumed to be due to changes in the levels of somatostatin-, motilin-, gastrin-, or VIP-immunore- active substances (IS) in plasma. ${ }^{14-18)}$ Furthermore, abnormalities of gastrointestinal function is presumed to result from obstruction of the autonomic nervous system and changes in hormone levels. Thus we examined the plasma levels of gut regulatory peptides (somatostatin, motilin, gastrin, and VIP).

Radioimmunoassays (RIA) to detect motilin have been developed by several groups using ${ }^{125}$ I-motilin. ${ }^{19-21)}$ However, in terms of safety, sensitivity, and ease of handling, RIA methods are still less than satisfactory. We developed a sensitive and specific double-antibody enzyme immunoassay (EIA) for detecting motilin, using motilin-linked $\beta$-D-galactosidase as a marker antigen, a secondary antibody-coated immunoplate, and 4-methylumbelliferyl- $\beta$-D-galactopyranoside as a fluorogenic substrate.

The purpose of this study was to describe the sensitive and specific EIA for detecting motilin and to determine the effects of Hange-shashin-to on plasma levels of gut regulatory peptides (somatostatin, motilin, gastrin, and VIP).

\section{MATERIALS AND METHODS}

Materials Hange-shashin-to (EK-14, lot 011A), prepared as a $3.8 \mathrm{~g}$ dried powder extract of Pinelliae Tuber $(5.0 \mathrm{~g})$, Scutellariae Radix $(2.5 \mathrm{~g})$, Zingiberis Rhizoma (2.5 g), Ginseng Radix (2.5 g), Glycyrrhizae Radix (2.5 g), Zizyphi Fructus (2.5 g), and Coptidis Rhizoma (1.0 g), was kindly supplied by Kanebo. (Tokyo, Japan). The placebo was only the additive to of the EK-14 formulation.

Synthetic human somatostatin, porcine motilin, gastrin I (G17), and VIP were purchased from the Peptide Institute (Osaka, Japan). Fragment mini gastrin I was purchased from Sigma Chemical (St. Louis, MO, U.S.A.). Motilin and VIP fragment peptides were supplied by Professor H. Yajima. (Kyoto University, Kyoto, Japan). Antisera to somatostatin (RA-08-108) were purchased from Cambridge Research Biochemicals (Cambridge, U.K.), motilin (Y121) from Yanaihara Institute (Shizuoka, Japan), and gastrin (A600/R1B) and VIP (A604/R1B) from Biogenesis (Poole, U.K.). All other 
reagents were of reagent grade and commercially available.

Volunteers Five healthy male volunteers (nonsmokers), aged 25-40 (median 26 years), participated in this study. Each subject received information about the scientific purpose of the study, which was approved by the Ethics Committee of Oita Medical University, and gave informed consent. No subject received any medication for one month preceding the test and no stimulator of gastrointestinal motility was administered to any subject during the study.

Study Schedule Hange-shashin-to at a dose of $6.0 \mathrm{~g}$ was administered orally. The same dose of placebo was also given to the volunteers. Venous blood samples from a forearm vein were taken before and $20-240 \mathrm{~min}$ after administration of the drug. All subjects ate lunch at $11: 45-12: 00$ and the study was carried out from 14:00 ( $2 \mathrm{~h}$ after lunch) until $18: 00$.

Preparation of Enzyme-Labeled Antigen Human somatostatin, porcine motilin, mini gastrin I, and fragment VIP $(11-28)$ were conjugated with $\beta$-D-galactosidase (Boehringer Mannheim, Mannheim, Germany) with $N$ - $(\varepsilon$-maleimidocaproyloxy) (EMC)-succinimide according to the methods of Kitagawa et al. $^{22}$ ) These peptides dissolved in $0.05 \mathrm{M}$ phosphate buffer, $\mathrm{pH}$ 7.0, were mixed with EMC-succinimide in tetrahydrofuran at $20^{\circ} \mathrm{C}$ for $40 \mathrm{~min}$. The EMCpeptides thus obtained were purified via separation on a Sephadex G-25 column. The purified EMC-peptide fractions were combined with $\beta$-D-galactosidase by mixing them at $20^{\circ} \mathrm{C}$ for $60 \mathrm{~min}$. The $\beta$-D-galactosidase conjugate was then applied to a Sephacryl S-300 column. The fractions containing $\beta$-D-galactosidase activity were collected and stored at $4{ }^{\circ} \mathrm{C}$ after the addition of bovine serum albumin (BSA) and sodium azide.

Assay Procedure for Somatostatin-, Motilin-, Gastrin-, and VIP-IS Peptide levels in plasma were measured using a sensitive EIA for somatostatin-, ${ }^{23)}$ gastrin- ${ }^{24)}$ and VIP-IS ${ }^{25}$ as previously described. The assay was performed using a delayed addition method. Separation of bound and free antigen was performed on an anti-rabbit IgG (55641) (ICN Pharmaceuticals, Aurora, Ohio, U.S.A.) coated immunoplate (Nunc-Immuno Module Maxisorp F8, InterMed, Denmark). ${ }^{26)}$

The assay buffer consisted of $0.05 \mathrm{M}$ phosphate buffer, $\mathrm{pH}$ 7.0, containing $0.5 \% \mathrm{BSA}, 1 \mathrm{~mm} \mathrm{MgCl}_{2}$, and 250 kallikrein inhibitor units $/ \mathrm{ml}$ of aprotinin (Trasylol, Bayer, Leverkusen, Germany). Antiserum (100 $\mu \mathrm{l})$ and sample (100 $\mu \mathrm{l}$, plasma extracts or standard) were mixed and incubated at $4{ }^{\circ} \mathrm{C}$ for $24 \mathrm{~h}$. Then diluted enzyme-labeled antigen $(50 \mu \mathrm{l})$ was added, and the solution was incubated at $4{ }^{\circ} \mathrm{C}$ for an additional $24 \mathrm{~h}$. One hundred microliters of the antigen-antibody solution for each sample was added to the secondary antibody-coated immunoplate. The plate was incubated at $4{ }^{\circ} \mathrm{C}$ overnight, washed with $0.01 \mathrm{M}$ phosphate buffer, $\mathrm{pH} 7.0$, containing $0.15 \mathrm{M} \mathrm{NaCl}$, and $0.05 \%$ Tween 20 , and then $200 \mu \mathrm{l}$ of $0.1 \mathrm{~mm}$ 4-methylumbelliferyl $\beta$-D-galactopyranoside (Sigma Chemical) in $0.05 \mathrm{M}$ phosphate buffer, $\mathrm{pH} 7.0$, containing $1 \mathrm{~mm} \mathrm{MgCl}_{2}$ was added to each well. The plate was incubated at $37^{\circ} \mathrm{C}$ for $180 \mathrm{~min}$. The fluorescence intensity $\left(\lambda_{\mathrm{Ex}}\right.$ $\left.360 \mathrm{~nm}, \lambda_{\mathrm{Em}} 450 \mathrm{~nm}\right)$ of the fluorescent product 4-methylumbelliferon was measured with a MTP-100F microplate reader (Corona Electric, Ibaraki, Japan).

Preparation of Plasma Extracts The blood samples were placed in chilled tubes containing 500 kallikrein inhibitor units $/ \mathrm{ml}$ of aprotinin and $1.2 \mathrm{mg} / \mathrm{ml}$ of EDTA. After centrifugation, plasma samples were diluted with $4 \%$ acetic acid, $\mathrm{pH}$ 4.0, loaded onto Sep-Pak C18 cartridges (Millipore, Milford, MA, U.S.A.), and washed with $4 \%$ acetic acid. The peptides in plasma were eluted with $70 \%$ acetonitrile in $0.5 \%$ acetic acid, $\mathrm{pH} 4.0$, lyophilized, reconstituted to $100 \mu \mathrm{l}$ with the assay buffer, and subjected to EIA. In the motilin EIA system, plasma samples were concentrated twice on Sep-Pak C18 cartridges. The recovery and reproducibility for human plasma with this motilin EIA were examined by adding standard solution to hormone-free plasma. ${ }^{27)}$

HPLC of Plasma Extracts HPLC was performed using a reverse-phase C18-packed column (Cosmosil 5C18-AR, Nacalai Tesque, Kyoto, Japan). The HPLC consisted of a model 600E pump system (Millipore). The plasma samples, purified on Sep-Pak C18 cartridges as described above, were reconstituted to the first composed mobile phase and passed through the column. Somatostatin-IS or motilin-IS was eluted with a linear gradient of acetonitrile (from 5\% to 55\% over $50 \mathrm{~min}$ ) in $0.1 \%$ trifluoroacetic acid. The flow rate was $1.0 \mathrm{ml} / \mathrm{min}$ and fraction size was $1.0 \mathrm{ml}$. Eluted fractions were concentrated by spin-vacuum evaporation, lyophilized, and stored $\left(-40^{\circ} \mathrm{C}\right)$ until EIA.

Data Analysis Somatostatin-, motilin-, gastrin-, and VIP-IS levels in plasma are expressed as concentration of mean \pm S.D. $(\mathrm{pg} / \mathrm{ml})$. Comparisons of mean values were made by analysis of variance and Dunnett's test. A value of $p<0.05$ was regarded as significant.

\section{RESULTS}

EIA for Motilin in Human Plasma Typical calibration curves for the motilin EIA are shown in Fig. 1. When plotted as a semilogarithmic function, a linear displacement of enzyme-linked motilin by motilin was noted between 35 and $650 \mathrm{pg} / \mathrm{ml}$. The minimum amount of motilin detectable by this EIA system was $3.5 \mathrm{pg}(1.4 \mathrm{pg} /$ well $)$.

The immunospecificity of the antiserum (Y121) was examined by EIA using motilin conjugated with $\beta$-D-galactosidase. The displacement curves of other endogenous peptides (motilin (1-16, 4-22, 9-22), somatostatin, gastrin, VIP, secretin, and substance $P$ ) are shown in Fig. 1. The carboxyterminal motilin fragments $(4-22,9-22)$ exhibited crossreactivity to synthetic motilin, but the amino-terminal fragment $(1-16)$ exhibited little cross-reactivity. Somatostatin, gastrin, VIP, secretin, and substance $P$ minimally inhibited the binding of motilin conjugated with $\beta$-D-galactosidase with the motilin antibody (86-94\%). Thus the motilin antiserum Y121 recognizes the carboxy-terminal region of motilin and can distinguish motilin from other gastrointestinal peptides.

Human plasma extracts were subjected to reverse-phase HPLC to assess the presence of motilin-IS molecular variants in human plasma. The elution profiles revealed the presence of one main immunoreactive peak, eluted at a position corresponding to standard motilin, and several minor peaks (Fig. 2 ). The recovery rates of human plasma motilin between the proposed detectable ranges $(50 \mathrm{pg} / \mathrm{ml}$ and $500 \mathrm{pg} / \mathrm{ml})$ with this EIA were $97.3 \%$ and $94.7 \%$. The reproducibility (CV \%) for human plasma $(50 \mathrm{pg} / \mathrm{ml}$ and $500 \mathrm{pg} / \mathrm{ml})$ with this motilin 


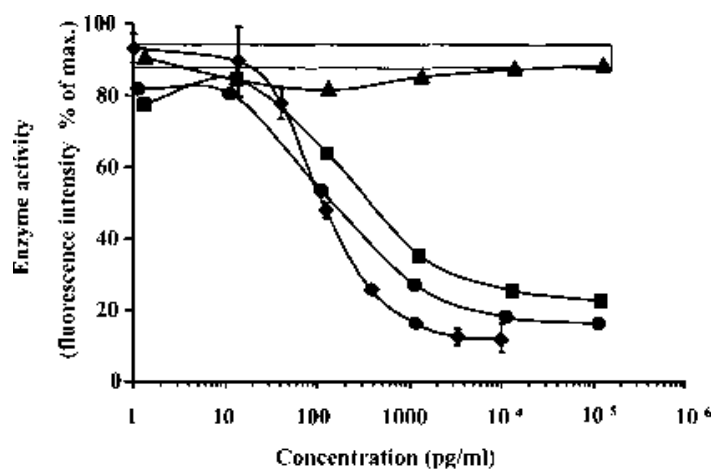

Fig. 1. Inhibition Curves of Motilin and Its Fragment Peptides in the EIA by Competition between Motilin Conjugated with $\beta$-D-Galactosidase toward Antiserum Y121

$\bullet$, motilin; $\boldsymbol{\Delta}$, motilin $(1-16)$; $\boldsymbol{\bullet}$, motilin $(4-22)$; $\mathbf{\square}$, motilin (9-22); $\square$, somatostatin, gastrin, VIP, secretin, and substance P. Motilin fragments were converted with motilin molecular weight.

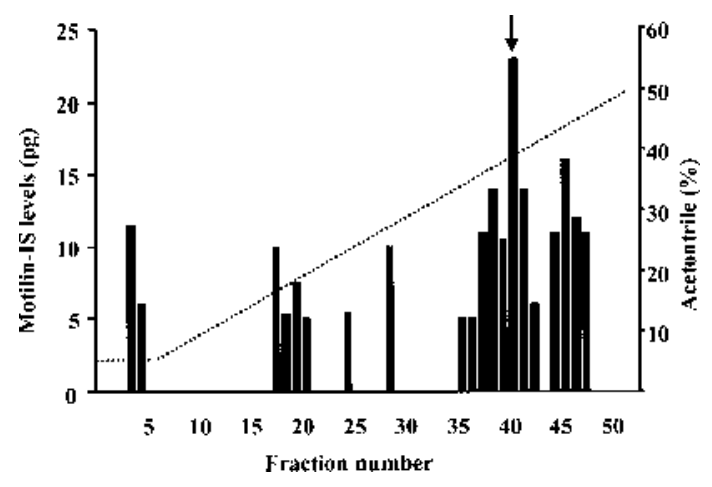

Fig. 2. HPLC Elution Profiles of Human Plasma

The dotted line indicates the acetonitrile gradient. Synthetic motilin was run in separate chromatographs under the same conditions, and indicated by the arrow.

EIA was $2.5 \%$ and $3.0 \%$ of innerassay $(n=5)$, and $4.9 \%$ and $5.7 \%$ of intraassay $(n=10)$ comparisons.

Effect of Hange-shashin-to on Plasma Somatostatin-, Motilin-, Gastrin-, and VIP-IS Levels The plasma somatostatin-IS level-time profile of Hange-shashin-to is shown in Fig. 3A. Hange-shashin-to caused significant increases in somatostatin-IS at 20 and 60 min compared with the response of the placebo group. At $40 \mathrm{~min}$, the volunteers had different degrees of increase in plasma levels after the administration of Hange-shashin-to.

The plasma motilin-IS level-time profile is shown in Fig. 3B. Plasma motilin-IS levels showed the periodicity in both the Hange-shashin-to and placebo groups and differed among volunteers. Hange-shashin-to caused significant increases in motilin-IS at $40 \mathrm{~min}$ and enhanced the secretion of motilin.

The plasma gastrin-IS levels after the administration of Hange-shashin-to are shown in Fig. 3C. Hange-shashin-to significantly increased gastrin-IS levels between $40-90 \mathrm{~min}$ compared with the response of the placebo group.

Hange-shashin-to had no significant effect on plasma VIPIS (Fig. 3D). Plasma VIP-IS levels in both groups remained within a small range (average, about $9 \mathrm{pg} / \mathrm{ml}$ ) before and after administration.

HPLC Chromatogram of Somatostatin-IS Levels in Plasma Hange-shashin-to caused an approximately 5-fold increase in somatostatin-IS at $20 \mathrm{~min}$ compared with the re-
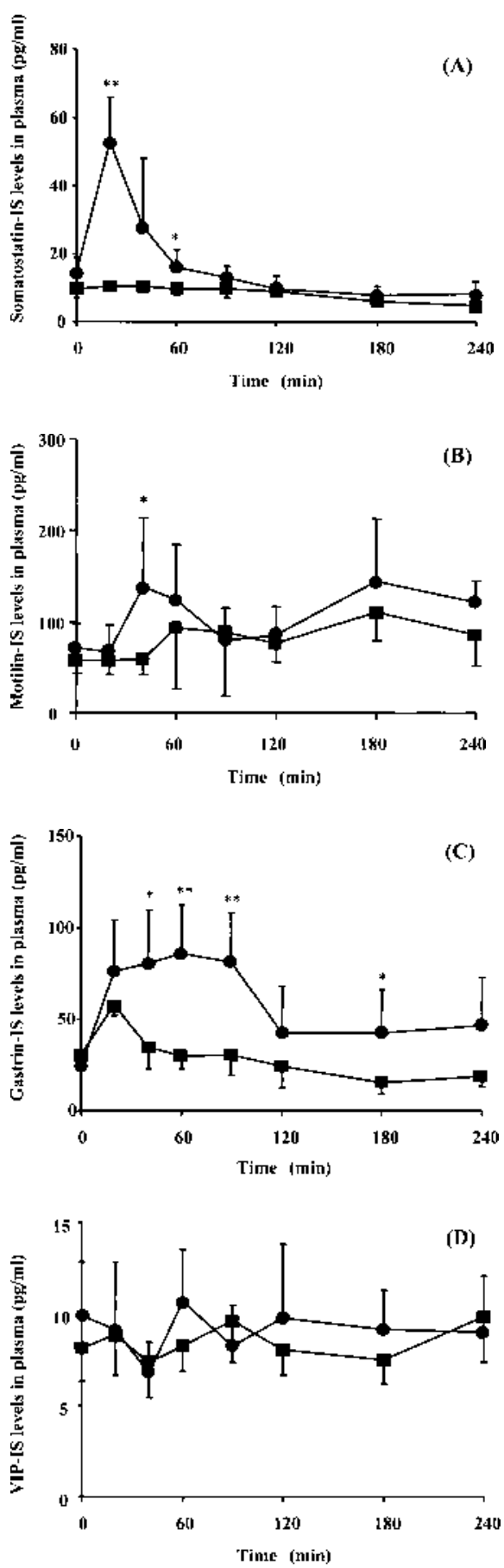

Fig. 3. Effect of Hange-shashin-to ( ) or Placebo ( $\square$ ) on Plasma Somatostatin- (A), Motilin- (B), Gastrin- (C), and VIP-IS (D) Levels

sponse of the placebo group. Figures $4 \mathrm{~A}$ and B shows the results when plasma extracts 20 min after administration were subjected to reverse-phase HPLC to assess the presence of somatostatin-IS molecular variants. The elution profiles revealed the presence of two main immunoreactive peaks, and one of the two peaks eluted at a position corresponding to that of somatostatin (fraction 39-41). The peak level of Hange-shashin-to corresponding to somatostatin was several fold larger than that of placebo. Furthermore, the other main unknown peak (dotted arrow, fraction 22-24) had the same tendency to increase as the peaks corresponding to somatostatin, and the unknown peak level of Hange-shashin-to 

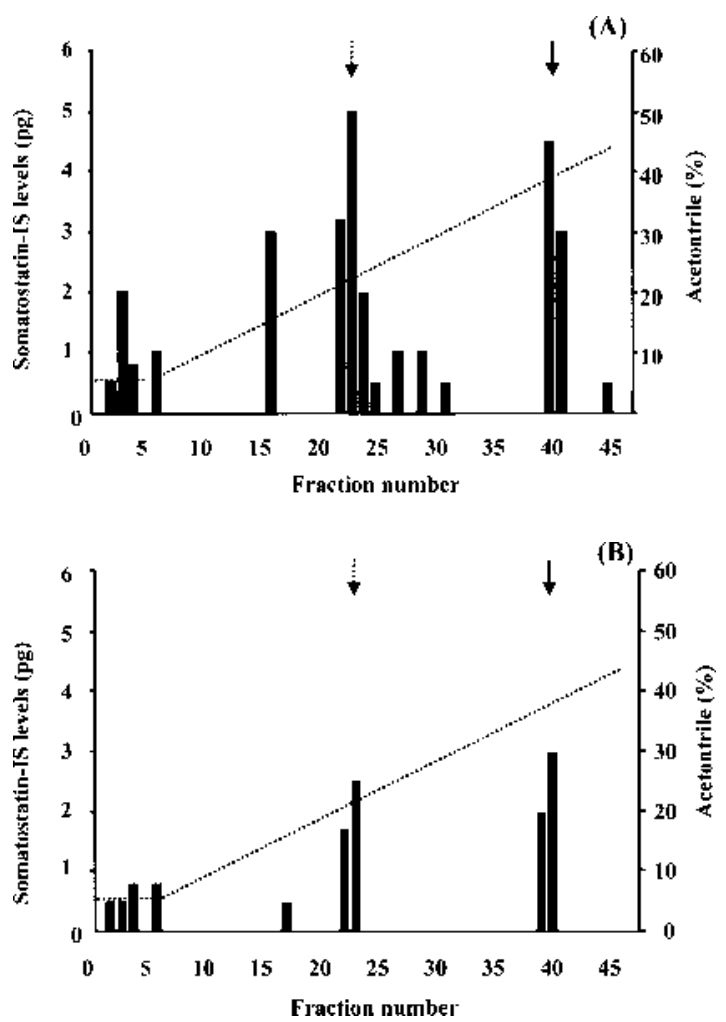

Fig. 4. Elution of Somatostatin-IS $20 \mathrm{~min}$ after oral Administration of Hange-shashin-to (A) or Placebo (B) from Reverse-Phase HPLC of Extracted Plasma

The dotted line indicates the acetonitrile gradient. Synthetic human somatostatin is indicated by the straight arrows. Dotted arrows are the other unknown somatostatin-IS peaks.

showed much larger increases compared with that of placebo.

\section{DISCUSSION}

Abnormalities of gastrointestinal motility are assumed to be caused by obstruction of the autonomic nervous system and variations in hormone levels. The gut regulatory peptides somatostatin, motilin, gastrin, VIP, etc. regulate gastrointestinal motility.

Using $\beta$-D-galactosidase-labeled motilin as a marker antigen, an anti-rabbit IgG-coated immunoplate as a bound/free separator, and 4-methylumbelliferyl $\beta$-D-galactopyranoside as a fluorogenic substrate, we developed a sensitive and specific EIA for the quantitation of motilin. Since 1975, RIA methods developed for motilin have been widely used, although, those methods have several disadvantages due to the use of radioisotopes. The EIA detailed in this report retains the advantages of the RIA system while minimizing the disadvantages. This EIA was sensitive $(3.5 \mathrm{pg}, 1.4 \mathrm{pg} / \mathrm{well})$ and specific (carboxy-terminal region) for motilin, and the sharp standard inhibition curve obtained was linear between 35 and $650 \mathrm{pg} / \mathrm{ml}$. The sensitivity of other immunoassays was reported to be $10 \mathrm{pg}$ (RIA) ${ }^{19)}$ and $5.4 \mathrm{pg}$ (EIA, recognition of amino-terminal region). ${ }^{28)}$ We applied the EIA to detect motilin-IS in human plasma. The recovery $(>90 \%)$ and reproducibility $(\mathrm{CV} \%$ of innerassay and intraassay comparisons) of this EIA with plasma samples were satisfactory. The plasma levels of this EIA after lunch $(2 \mathrm{~h}$, samples at $0 \mathrm{~min})$ were $64.2(40.0-102.5) \mathrm{pg} / \mathrm{ml}$. The detectable

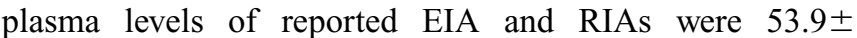
$25.6 \mathrm{pg} / \mathrm{ml}$ (mean \pm S.D. $){ }^{28)} 194.4(13.5-810) \mathrm{pg} / \mathrm{ml},{ }^{20)}$ and $78.0(49.1-124.0) \mathrm{pg} / \mathrm{ml}^{29}{ }^{29}$ Human plasma levels in our EIA were nearly equivalent to those of previously reported EIA and RIA methods.

In this study, Hange-shashin-to enhanced somatostatin-IS and motilin-IS levels. Increases in somatostatin and motilin might correspond with gastrointestinal motility regulation by accelerating gastric emptying. Hange-shashin-to has been reported to have prokinetic activity and to be useful in treating chronic dyspepsia, as is Rikkunshi-to. The acetaminophen absorption method confirmed those effects of the medicine. ${ }^{30)}$ When we assessed the presence of somatostatin-IS molecular variants in plasma extracts at $20 \mathrm{~min}$, the elution profiles revealed the presence of two main immunoreactive peaks, one of which eluted at a position corresponding to that of somatostatin. In this study, blood samples were taken from a forearm vein. Changes in hormone levels in peripheral veins might differ somewhat from those in local gastrointestinal organs. Therefore we assumed that difference in the other unknown peak level (fraction 22-24, Figs. 4A and B) between the Hange-shashin-to and placebo groups was greater than that in the peak level corresponding to somatostatin (fraction 39-41, Figs. 4A and B). Somatostatin participates in regulating gastrointestinal motility (MMC-like activity) with motilin. Motilin is a powerful inducer of gastrointestinal motor activity. In our study, periodic rhythms of motilin-IS might have obscured the increases in MMC activity partially.

Hange-shashin-to regulates the lower as well as upper gastrointestinal tract. This medicine is effective in the treatment of irritable bowel syndrome (IBS), which is believed to result from dysfunction of the lower gastrointestinal tract. ${ }^{31)} \mathrm{A}$ somatostatin analogue has been approved for the therapy of IBS. $^{32,33)}$ Recently, Hange-shashin-to has also been reported to be effective against diarrhea as a side effect of carcinostatic drugs since it balances the prostaglandin $\mathrm{E}_{2}$ level and water absorption. ${ }^{13,34)}$ In this study, increases in somatostatinIS levels may be one pathway for motor regulation of the lower gastrointestinal tract.

Gastrin stimulates acid secretion and its release is mediated by various mechanisms. Dyspepsia, one indication for Hange-shashin-to, is closely related to abnormalities of gastrointestinal motility and hypoacidity. Stimulation of the gastric mucosal $G$ cells by Hange-shashin-to might directly result in the early elevation (nonspecific) of gastrin and then some pathways might stimulate G cells continuously (specific). Gastrin release stimulated by Hange-shashin-to and by Rikkunshi-to might be related to normalization of gastric functions.

Ninjin-to ${ }^{14)}$ and Rikkunshi-to, ${ }^{15)}$ which improve gastrointestinal motor dysfunction, cause increases plasma somatostatin-IS and/or motilin-IS levels. Hange-shashin-to has been evaluated clinically as more effective in the treatment of chronic hypofunction of the gastrointestinal tract than Rikkunshi-to in the treatment of hyperfunctioning conditions. The changes in somatostatin-IS levels after the administration of Hange-shashin-to were greater than those after Rikkunshi-to. However, the changes in the gastrin-IS levels were approximately the same after the administration of both Hange-shashin-to and Rikkunshi-to. Their different indications in Kampo medicine might be based on the different ef- 
fects on hormone levels. The regulatory mechanisms of the gastrointestinal tract by Hange-shashin-to and Rikkunshi-to are not known. Reports on the herbs that constitute these Kampo medicines indicate that Ginseng Radix and Zingiberis Rhizoma accelerate gastrointestinal motility and that Glycyrrhizae Radix and Zizyphi Fructus support those effects, while Pinelliae Tuber accelerates gastric emptying. ${ }^{35)}$ Hange-shashin-to, Ninjin-to, and Rikkunshi-to had no effects on VIP-IS levels in plasma and the effects differed from those of Dai-kenchu-to. ${ }^{18)}$

Hange-shashin-to regulates both upper (prokinetic action) and lower (regulation of motility) gastrointestinal functions. In this study, Hange-shashin-to changed levels of the gut regulatory peptides somatostatin-, motilin-, and gastrin-IS. Changes in these peptides stimulated by Hange-shashin-to might suggest the pharmacological activity of this medicine.

\section{REFERENCES}

1) Peeters T. L., Janssens J., Vantrappen G. R., Regul. Pept., 5, 209-217 (1983).

2) Poitras P., Steinbach J. H., VanDeventer G., Code C. F., Walsh J. H., Am. J. Physiol., 239, G215-220 (1980).

3) Thor P., Krol R., Konturek S. J., Coy D. H., Schally A. V., Am. J. Physiol., 235, E249-254 (1978).

4) Hostein J., Janssens J., Vantrappen G., Peeters T. L., Vandeweerd M., Leman G., Gastroenterology, 87, 1004-1008 (1984).

5) Seal A., Yamada T., Debas H., Hollinshead J., Osadchey B., Aponte G., Walsh J., Am. J. Physiol., 243, G97-102 (1982).

6) Johanssson C., Efendic S., Wisen O., Uvnas-Wallensten S., Luft R., Scand. J. Gastroenterol., 13, 481-483 (1978).

7) Shulkes A., Baillieres Clin. Endocrinol. Metab., 8, 215-236 (1994).

8) Itoh Z., Honda R., Hiwatashi K., Takeuchi S., Aizawa I., Takayanagi R., Couch E. F., Scand. J. Gastroenterol. Suppl., 39, 93-110 (1976).

9) You C. H., Chey W. Y., Lee K. Y., Gastroenterology, 79, 62-66 (1980).

10) Matsuno M., Matsui T., Iwasaki A., Arakawa Y., J. Gastroenterol., 32, $579-586$ (1997).

11) Goyal R. K., Rattan S., Said S., Nature (London), 288, 378-380 (1980).

12) Grider J. R., Cable M. B., Bitar K. N., Said S. I., Makhlouf G. M., Gastroenterology, 89, 36-42 (1985).
13) Kase Y., Hayakawa T., Aburada M., Komatsu Y., Kamataki T., Jpn. J. Pharmacol., 75, 407-413 (1997).

14) Naito T., Nagano T., Itoh H., Takeyama M., Biol. Pharm. Bull., 24, 194-196 (2001).

15) Naito T., Itoh H., Yasunaga F., Takeyama M., Biol. Pharm. Bull., 24, $841-843$ (2001).

16) Nagano T., Itoh H., Takeyama M., Biol. Pharm. Bull., 22, 1131-1133 (1999).

17) Sugiyama M., Moriwaki Y., Ito S., Hamahata Y., Fukuda N., Tanaka S., Prog. Med., 13, 1085-1088 (1993).

18) Nagano T., Itoh H., Takeyama M., Biol. Pharm. Bull., 23, 352-353 (2000).

19) Dryburgh J. R., Brown J. C., Gastroenterology, 68, 1169-1176 (1975).

20) Bloom S. R., Mitznegg P., Bryant M. G., Scand. J. Gastroenterol. Suppl., 39, 47-52 (1976).

21) Lee K. Y., Chey W. Y., Tai H. H., Yajima H., Am. J. Dig. Dis., 23, $789-795$ (1978).

22) Kitagawa T., Shimozono T., Aikawa T., Yoshida T., Nakamura H., Chem. Pharm. Bull., 29, 1130-1133 (1981).

23) Takeyama M., Yanaga N., Yarimizu K., Ono J., Takaki R., Fujii N., Yajima H., Chem. Pharm. Bull., 38, 456-459 (1990).

24) Takeyama M., Matsuo H., Mori K., Chem. Pharm. Bull., 41, 21972199 (1993).

25) Takeyama M., Wakayama K., Takayama F., Kondo K., Fujii N., Yajima H., Chem. Pharm. Bull., 38, 960-962 (1990).

26) Takeyama M., Kondo K., Hayashi Y., Yajima H., Int. J. Pept. Prot. Res., 34, 70-74 (1989).

27) Tai H. H., Chey E. Y., Anal. Biochem., 87, 376-385 (1978).

28) Takeyama M., Asakura S., Kawano A., Mori K., Biol. Pharm. Bull., 17, 440-442 (1994).

29) Teufel M., Luik G., Niessen K. H., Monatsschr Kinderheilkd, 134, 132-137 (1986).

30) Harasawa S., Miwa T., Prog. Med., 13, 2533-2539 (1993).

31) Satomi M., Kitano A., Ohtani T., Kikkawa N., Mizuno S., Murai M., Sujishi M., Kanai H., Itoh N., Inatsugi N., Shimizu K., Kampo-Igaku, 11, 26-32 (1987).

32) Hasler W. L., Soudah H. C., Owyang C., J. Pharmacol. Exp. Ther., 268, 1206-1211 (1994).

33) De Schryver A. M., Samsom M., Scand. J. Gastroenterol. Suppl., 232, $38-42$ (2000).

34) Kase Y., Hayakawa T., Ishige A., Aburada M., Komatsu Y., Biol. Pharm. Bull., 20, 954-957 (1997).

35) Fujii H., "Kampoigaku III," Nihonkampoigakukenkyusho, Tokyo, 1980, p. 71. 